\title{
On the Significance of Learner Strategies in English Reading on Learners' Language Achievement
}

\author{
Hui He \\ The Academy of Armed Forces Engineering, Beijing, China \\ Caixia $\mathrm{Hu}$ \\ College of Arts, China University of Petroleum, Qingdao, China \\ Hua Liu \\ The Academy of Armed Forces Engineering, Beijing, China
}

\begin{abstract}
Strategies are often seen as ways used by language learners for getting out of trouble in language study in the short term, but a more positive view might be that successful strategies used by learners can promote longer term language development. This article explores the research evidence for benefits that strategy use in reading can bring in learners' language achievement in both the short term and the long term.
\end{abstract}

Index Terms - learner strategy, reading, teaching practice

\section{INTRODUCTION}

The main purpose of this article is to review current perspectives on learner strategies and have a look at the application of learner strategies in reading. Furthermore, it attempts to make a tentative discussion about the significance of learner strategies in reading on language learners' achievement both in short term and long term and testify these strategies in the author's own reading teaching practice.

This paper is composed of four parts. A brief introduction about the theoretical background of learner strategies is given in the first part of the paper. Part two concerns itself with reading strategies and their significance on learners' reading comprehension with some research evidence in reading. The application of the reading strategies to the author's own reading teaching material compared with the author's previous teaching method of this material forms the focus of part three. Part four ends the whole paper with the conclusion that learner strategies play an effective role in improving learners' language achievement and shed light on the teaching of reading. It also points out that cognitive, metacognitive, and social and affective strategies should be integrated together when they are applied in practice instead of overemphasizing or neglecting any of them.

\section{THEORETICAL FOUNDATION}

\section{A. Definition of Language Learner Strategies}

Teachers and researchers have found it amazing that some language learners are more successful than others in learning a foreign or second language even if they have the same instructors, in the same learning environment and at the same language level. What attributes to their success? Do they adopt some special and effective methods or strategies in their study? If so, what are they? A number of researchers have done a great deal of work in this field and found that learners do apply some strategies while learning a second language and these strategies can be identified and classified (O’Malley \& Chamot, 1990, p. 3 ). But first of all, what is learner strategy?

As for the definition of learner strategies, different researchers proposed different versions. Focusing on the function of learner strategies, Cohen defined learner strategies in 1998 as

Second language learner strategies encompass both second language learning and second language use strategies. Taken together they constitute the steps or actions consciously selected by learners either for the learning of a second language, the use of it, or both (Macaro, 2001, p. 17).

In 1990, Oxford made an expansion of these definitions, which is more detailed and clearer, by saying that

Learning strategies are specific actions taken by the learner to make learning easier, faster, more enjoyable, more self-directed, more effective, and more transferable to new situations (Oxford, 1990, p. 8).

Although the concept of learner strategies was analyzed from different perspectives, Wenden, Cohen and Oxford all agree that learner strategies are something learners take to facilitate their learning.

B. Research History of Learner Strategies 
In terms of the history of strategy research, Wenden \& Rubin (1987) gave a general review on the development of learner strategies. They point out that Aaron Carton initiated research on learner strategies by publishing his study The Method of Inference in Foreign Language Study in 1966 (Wenden \& Rubin, 1987, p. 19). In this article, Carton first takes making inference as a strategy used by second language learners and regards language learning as a kind of problem-solving process.

Following Carton, researchers did various studies on learner strategies from different perspectives. Some researchers concentrate on identifying and analyzing the strategies used by successful language learners. One of the researchers working in this field is Rubin, who made great contribution to learner strategies research. She proposed a classification system of strategies in terms of processes which may contribute directly to learning and those that may contribute indirectly to learning in 1981 (Wenden \& Rubin, 1987, p. 20). Her article "What the "Good Language Learner" Can Teach Us' published in 1975 is regarded as the birth of language learner strategies research (Cohen \& Macaro, 2007, p. $11)$.

At about the same time, Stern and Naiman also conducted research on the strategies that good language learners employ in their learning. Stern listed the top-ten strategies which are necessary to attain second language competence (ibid). In order to match his research data with Stern's list, Naiman modified these ten strategies to five general strategies and related techniques (Wenden \& Rubin, 1987).

In much of later research on learner strategies, researchers explored the evidence of the link between strategies and learners' achievement from other perspectives. Wong-Fillmore stressed social strategies in the process of language learning (Cohen \& Macro, 2007, p. 13), while Bialystok examined the effects of two particular kinds of strategies: functional strategies and formal strategies (Wenden \& Rubin, 1987, p. 21). More specifically, Taron studied the communication strategies used by second language learners (ibid). Another important figure is Hosenfeld, who contrasted the successful second language learners with those unsuccessful ones on reading strategies they adopted respectively by using the "think aloud" type of introspection (Cohen \& Macaro, 2007, p. 189). More recently, Wenden emphasized the importance of metacognitive strategies in second language learning (Wenden \& Rubin, 1987, p. 22).

\section{Classification of Learner Strategies}

During the 1970s and 1980s, a large number of researchers conducted various studies on learner strategies. Based on the findings of their studies, they proposed different categorization systems of learner strategies. Some representative ones are as follows.

Rubin first classified learner strategies into two kinds based largely on the interviews with good language learners: strategies directly affect learning and strategies that contribute indirectly to learning (O'Malley \& Chamot, 1990). According to Rubin, the former includes clarification, monitoring, memorization, guessing/inductive inferring, deductive reasoning and practice, and the latter contains creating opportunities for practice and production tricks.

O'Malley and Chamot proposed that learner strategies could be divided into three categories: cognitive strategies, metacognitive strategies and social/affective strategies (O’Malley \& Chamot, 1990, p. 44). According to them (1990), cognitive strategies involve processing language in brain, such as rehearsal, organization, inferencing, summarizing, deduction, transfer and elaboration; metacognitive strategies involve thinking about learning processes, monitoring learning tasks and deal with planning, monitoring, and evaluating the cognitive processes. They are exemplified by planning, setting goals and self-management; and social/affective strategies refer to all the means of dealing with affective and social aspects in language learning situations, such as cooperation, questioning for clarification and self-talk in the learning process (O'Malley \& Chamot, 1990, p. 137-139). The exact strategies of each category are shown in Appendix 1.

Another researcher providing a classification scheme for strategies is Oxford, who further developed the definition and categorization of learner strategies. She classified learner strategies into two classes: direct strategies and indirect strategies, which are subdivided into six groups: 'memory, cognitive, and compensation under the direct class; metacognitive, affective, and social under the indirect class' (Oxford, 1990, p. 14). It is obvious that Oxford's classification of learner strategies has much in common with that of O'Malley and Chamot.

Personally, I prefer O'Malley and Chamot's classification of learner strategies because they can be relatively easily identified and categorized in teachers' teaching practice compared with those of Oxford. In addition, Rubin's categorization seems not so overall to me because it is emerged from the observation of only successful language learners.

\section{DISCUSSION}

\section{A. Theoretical Introduction about Reading Strategies}

As for the definition of reading strategies, Cohen claims that reading strategies are the mental processes that readers consciously employ in accomplishing reading tasks (Cohen \& Macaro, 2007, p. 190). To better understand reading strategies, it is necessary to review reading models at first because different reading strategies may be employed in different reading processes.

Researchers established several reading models which describe the reading process when people read. Barnett provides a detailed description of these reading models: bottom-up theory, top-down theory and the interactive school 
(Richards, 1997, p. 18). As Barnett states, bottom-up processes indicate that the reader comprehend a text from the smallest units, such as words or phrases, on the contrary, in top-down processes the reader bring a great deal of background knowledge to the text and 'discern meaning at whole text-level to support comprehension'. These two models of reading appeared earlier than the interactive model which supports that both bottom-up and top-down processes occur simultaneously or alternatively in the process of reading (ibid).

Then what strategies do successful readers employ in their reading to enable them to comprehend a text well? Anderson et al. provided a list of reading strategies that good readers use, such as using text features (subheadings, transitions, etc.), using world knowledge, monitoring comprehension (Anderson et al. 1991, cited by Richards, 1997, p. 16).

O'Malley and Chamot have also observed that the principle strategies used for reading comprehension are inferencing, deduction, elaboration, transfer, substitution, cooperation and self-evaluation (O'Malley \& Chamot, 1990, p. 178-179).

\section{B. On the Significance of Reading Strategies Based on Researches into Reading Strategy Instruction}

A great deal of research has been made to improve the reader's reading comprehension ability through the reader's use of some effective reading strategies. As I teach English in a university, I will mainly focus on some studies on university students.

Kitajima is one of these researchers. He designed a program involving US university students of Japanese and in the program a combination of word-level and metacognitive strategies was used (Cohen \& Macro, 2007, p. 201). The instruction includes identifying referents in text which involves strategies at syntax and discourse level. After a period of 15 weeks, Kitajima found the intervention group made better achievements on all the pos-tests than the comparison group. The findings of this research indicate that students could successfully learn to use a reading strategy and improve their comprehension accordingly. As for the significance of these strategies, I think the strategies at syntax and discourse level and metacognitive strategies may have a long-term effect on improving the reader's comprehension because these kinds of strategies guide the reader to focus on the bigger units of a text instead of smaller ones. That will be helpful for the reader to form a good habit of reading a text from a top-down process. However, such kinds of reading strategies instruction will be a challenge for the language teachers. And it will also take quite a long time for students to be able to apply these strategies automatically in their reading.

A similar research was carried out by Kern, who organized a reading strategy instruction program with the attempt to develop university students' reading comprehension ability (Cohen \& Macro, 2007). The reading strategies involved in this program include word recognition, inferring meaning, and engaging in synthesis-of-meaning. Kern divided 53 university students into experimental and control groups. After a period of time, he found that only the lower-ability students improved significantly in comprehension. Kern summarized that higher-levels students had already used the strategies instructed and suggested that students should get appropriate reading strategies from the very beginning. In my view, reading strategies adopted in this research, such as word recognition, inferring meaning and engaging in synthesis-of-meaning may be beneficial to students in short term. From the research, it can be found that after students received a certain degree of such kinds of strategies instruction they wouldn't make much obvious improvement any more.

Carrell, Pharis, and Liberto conducted a study to measure the effects of two metacognitive strategies on students' reading comprehension (Cohen \& Macaro, 2007). There were two intervention groups in this study, one was taught pre-reading semantic mapping of information concluded from the text, the other was taught to activate students' previous knowledge about the topic of the text before reading. They found significantly that both types of reading strategies successfully improved students' reading comprehension. Personally, I regard these two types of reading strategies as very useful methods to improve students' reading comprehension, especially semantic mapping. It is not only effective in reading but also in writing by helping students to form a good sense of text structure. Therefore, semantic mapping may bring benefits both in reading and writing in short term as well as in long term, and activating students' background knowledge about the topic of the text before reading as a top-down strategy may also work effectively both in short term and long term. These two strategies will be applied in my intensive reading teaching in future.

\section{REFLECTION AND CONCLUSION}

\section{A. The Teaching Method I Used in the Past}

I teach first-year students intensive reading in a university of China. The chosen teaching reading material is the first volume of College English which is widely used in universities of China. Unit four Turning Off TV: A Quiet Hour (see Appendix 2) of this book is taken as the sample text to illustrate how reading strategies will be applied in class.

Before I learn about the knowledge of learner strategies, I think I put too much attention on the grammatical points with neglecting the impact of reading strategies on the students' reading proficiency. Most of my teaching is test-oriented. I taught Unit 4 in the following process in the past:

\section{Warming-up stage}

Propose a topic related to the title of the text: What do you think of the role that TV plays on people's life, positive or 
negative? Why? Leave 10 minutes at the beginning of the class for the students to discuss the topic and then ask them to speak out voluntarily. The class lasts for 50 minutes. Because of the limited time, 10 minutes may not be enough for students to discuss and speak out their opinions. Whether there are actively enough to share their ideas in public depends on whether they are interested in the topic and the task difficulty. Sometimes it may take me a few minutes to encourage some volunteers.

\section{Comparison with the author's idea}

Introduce the title of the text and guide the students to find out the author's opinion on the topic they were just discussing. Provide the students with a chance to compare their views with the author's.

\section{Vocabulary and grammar-focus instruction}

The grammatical points and difficult vocabulary which may hinder students from understanding the text will be illustrated with examples in detail. In most cases, the words and the grammatical points required in the College English Test (CET) syllabus are overemphasized.

\section{Paraphrasing}

Ask the students to paraphrase some important sentence structures and vocabularies. Encourage them to use synonyms, antonyms and the words and sentence structures they have learnt before when they are paraphrasing.

\section{Summary stage}

Ask the students to summarize the main idea of each paragraph and the whole text. They are also expected to be able to analyze the general structure of the text.

\section{Practice}

Instruct the students to do some exercises related to some important vocabulary, grammar, sentence structure of this lesson, such as vocabulary match, blank-filling, paraphrasing, cloze and translation.

\section{Second passage study}

This is the part that I always overlook in my teaching. The second passage usually has the same topic as the first one but a little easier than the first one. I always give a simple explanation about the main idea of the text without a detailed explanation about the grammar as I do in the first passage. Actually, there is an introduction about a certain kind of reading strategies before the second passage in each unit. Before I learn about reading strategies, I consider this part as something studied by the students themselves after class. In fact, it is a part of strategy training implementation and the second passage is designed specially for practice those reading strategies.

\section{B. Revision of My Teaching with the Application of Reading Strategies}

As a number of studies (shown in the above discussion) have been done on the effectiveness of learner strategies in second language acquisition, many researchers advocate that teachers should provide students with direct training on strategy use either in classroom teaching or outside the classroom. As O'Malley and Chamot have reported some of the findings in the learner strategies research, the performance of L2 students instructed to use strategies with second language acquisition tasks is superior to those who received no such training (O'Malley and Chamot, 1990, p. 225). Beyond O'Malley and Chamot, Oxford also argued that strategy training is especially necessary in second and foreign languages acquisition, what is more, it should be highly practical and useful for students rather than being abstract and theoretical (Oxford, 1990, p. 201). Bearing the above discussion in mind, I intend to make some changes in the teaching of the text Turning Off TV: A Quiet Hour as follows and a number of metacognitive, cognitive, and social and affective strategies are immersed in the teaching process:

\section{Setting a top-down task}

This task is actually the same as the warming-up stage of the former one. I will choose a topic related to the content of the text, and then ask the students working in groups to express their opinions on that issue with their background knowledge. I regard this stage as a smooth transition from the students' general knowledge to the specific text. It is a good way to attract the students' attention to the text that they are going to learn. But usually it depends on whether the topics are interesting or not and whether the task difficulty is suitable for them.

\section{Signpost questions, advance organization and selective attention}

Prepare some questions about the text for the students. The purpose is not to test but to guide the students and help to direct their attention to the important points in the text. By doing that, I hope to give the students an overview of the text's structure and help them to better understand the main idea of the text. I will use advance organization by asking the students to skim the text quickly and make a selective attention to scan specific information related to the signpost questions.

\section{Identifying and explaining language points with the strategies of inference}

Explain the new vocabulary and grammatical points with the strategy of inferring from the context instead of telling students what they mean directly. Vocabulary and grammar have traditionally been the major component in English teaching programs in China and still retain this position today. But I will advise my students to reduce their dependence on English-Chinese bilingual dictionary. In addition, I will encourage them making inferences about the meanings of new vocabularies from context instead of looking up every new word and making vocabulary lists to learn by heart. Personally, I think a certain extent of tolerance of ambiguity should be allowed and encouraged as long as the new words do not prevent the readers' comprehension of the passage. Training them to infer meaning from context and ignore those unimportant new words, which Nuttall (1982) label as 'throwaway vocabulary', will greatly speed up their 
reading. Taking notes while they are reading can be helpful for them to find the key points and the structure of the passage. However, as my students only have 4 English classes each week and 45 minutes each class, it is impossible to carry these reading strategies on during the class. These strategies are expected to be employed by the students automatically not only in class but also after class as well.

\section{Producing summaries with semantic map, text diagram or table of contents}

When I finish explaining the whole text, I will ask the students to draw a semantic map, text diagram or a table of the content or just a few sentences to summarize the main idea of the text. On the one hand, that is because I believe these strategies will provide a helpful way of probing into text organization, thus it can add to students' understanding of the whole text. On the other hand, they are also beneficial to students' writing. Personally, I prefer semantic map and always use it as a way to analyze how the writer composes an article and an effective way to help me construct the outline of my essays. However, these strategies may be limited to those able and high-motivated students mainly because of the task difficulty.

\section{Self-evaluation and self-monitoring}

The students will be asked to self-evaluate their comprehension of the text by doing some exercises, such as multiple choice, matching or answering questions about the text. In this process, students will be able to find out their problems and consequently direct them to self-monitor their learning process, integrating the processes of self-evaluation and self-monitoring together automatically.

\section{Specific introduction of the reading skill: using context clues for word meanings}

Each unit of this textbook provides a special introduction of a certain kind of reading skill which I neglect in the past. Before I learn about learner strategies, I have never realized the benefit of this part and just ask the students to read it after class. And I believe most of them didn't have a look at this part partly because of my attitude to it. After introducing the reading attack skill, I will ask the students to use this reading skill when they read the second passage in order to enhance their understanding of the skill.

7. Social and affective strategies implementation: questioning for clarification, cooperation and lower students' anxiety

Although these kinds of strategies don't make a direct impact on improving the readers' reading ability, they can help students to comprehend a text better with non-linguistic aid and learn to cooperate with others. As a result, it can help the readers have a comprehensive understanding of the reading materials, and accordingly relieve their anxiety in the study.

\section{Conclusion}

This essay provides a rough review of the theoretical background and research history of learner strategies. Furthermore, it has a specific look at the application of these strategies in the field of reading and an introduction about reading strategies and their application in practice go into detail. As the importance of strategies application and training has been gradually recognized and proved by more and more researchers, the author makes a tentative application of these reading strategies to her own teaching practice and believes that students will benefit from the strategy training. Yet the important point to note is that teachers should focus on the integration of all types of reading strategies: cognitive, metacognitve, and social and affective rather than overemphasize or ignore a certain kind of strategy. It should also be pointed out that the application of these strategies in teaching practice may not be realistic in some teaching contexts. Some variables, such as learner's learning ability, motivation and teaching context should be taken into consideration.

\section{REFERENCES}

[1] Cohen, A \& Macaro, E. (Eds). (2007). Language Learner Strategies: Thirty Years of Research and Practice. Oxford: Oxford University Press.

[2] Macaro E. (2001). Learning Strategies in Foreign and Second Language Classrooms. London: Continuum.

[3] Nuttall, C. (1996). Teaching Reading Skills in a Foreign Language. Oxford: Heinemann.

[4] O’Malley, J. \& Chamot, A. (1990). Learning Strategies in Second Language Acquisition. Cambridge: Cambridge University Press.

[5] Oxford, R. (1990). Language Learning Strategies: What Every Teacher Should Know. Boston, Mass: Heinle \& Heinle.

[6] Richards, J. (1997). From Reader to Reading Teacher. Cambridge: Cambridge University Press.

[7] Wenden, A. \& Rubin, J. (1987). Learner Strategies in Language Learning. London: Prentice/Hall International.

[8] Williams, M. \& Burden, R. (1997). Psychology for Language Teachers. Cambridge: Cambridge University Press.

[9] Zai Xiangjun \& Zhang Zengjian. College English. 1vol. Shanghai: Shanghai Foreign Education Press.

Hui He was born in Zhoukou, Henan Province, China, in 1975. Her main research interests are linguistics and EFL teaching. She is a lecturer in the Academy of Armored Forces Engineering, Beijing, China. From Sep 30, 2008 to Sep 30, 2009, she was studying English teaching at Warwick University, UK and got her master degree there. In recent years, she has taken a keen interest in English grammar teaching and research, and published more than 6 related papers. 
Caixia Hu is a lecturer at College of Arts, China University of Petroleum, China. Her research interests mainly include EFL teaching and learning in China's context, and literature.

Hua Liu is an assistant professor in the Academy of Armored Forces Engineering, Beijing, China. She is the dean of the Foreign Languages Department in the university. Her main research interests are applied linguistics and EFL teaching. 